\title{
O uso da tradução automática e da aprendizagem baseada em projetos na produção de gêneros textuais escritos
}

\author{
The use of machine translation and project-based learning in the \\ production of written text genres
}

Aline Provedel Dib1

\begin{abstract}
Resumo
O objetivo deste trabalho é apresentar uma prática de sala de aula que envolve ensino de inglês como língua adicional, tradução e produção textual, usando componentes da aprendizagem baseada em projetos (FRIED-BOOTH, 2002; LEFFA; IRALA, 2014; STOLLER, 2006). A partir da análise de necessidades (HUTCHINSON; WATERS, 1987) dos estudantes do último ano do Ensino Médio/Técnico Integrado em Eletrônica, o gênero textual escolhido para ser elaborado como produto final do projeto foi o abstract. Ademais, o projeto incluiu a produção de resumos e resenhas críticas de livros e séries devido ao interesse dos alunos por esses assuntos. Diante de uma turma que apresentava diferentes níveis de proficiência linguística, discutir com os alunos sobre a prática tradutória e o uso do Google Tradutor foi uma forma de inclusão e reflexão sobre as línguas. Além disso, tal diversidade orientou minha escolha pela aprendizagem baseada em projetos, a qual possibilitou diferentes formas de engajamento. Durante a produção dos textos propostos, reflexões de ordem política, social, cultural e linguística emergiram. Por fim, pela qualidade dos textos apresentados e pelo retorno dos alunos acerca da atividade, pode-se dizer que foi uma experiência exitosa.
\end{abstract}

Palavras-chave: Tradução Automática. Aprendizagem baseada em projetos. Produção textual.

\begin{abstract}
This paper aims to present a classroom project that involves teaching English as an additional language, translation and text production through project-based learning components (FRIED-BOOTH, 2002; LEFFA; IRALA, 2014; STOLLER, 2006). Based on the needs analysis (HUTCHINSON; WATERS, 1987) of a group of high school students who were in the last year of a technical course in Electronics, the abstract was the text genre chosen to be developed as the final product of the project. Besides, the production of summaries and critical reviews of books and series was included in the project due to students' interest in these subjects. Once students presented different levels of language proficiency, discussing about translation practices and the use of Google Translate was a way of inclusion and reflection about languages. In addition, such diversity oriented my choice towards project-based learning, which enabled different forms of engagement. During the production of the proposed texts, political, social, cultural and linguistic reflections emerged. Finally, due to the quality of the texts presented and the students' feedback on the activity, it can be evaluated as a successful experience.
\end{abstract}

Keywords: Machine translation. Project-based learning. Text production.

\section{Introdução}

O objetivo deste trabalho é apresentar uma prática de sala de aula que, utilizando-se de componentes da aprendizagem baseada em projetos (ABP), envolveuo ensino de inglês como língua adicional, o uso da tradução através da ferramenta Google Tradutor (GT) e a produção de textos escritos de três diferentes gêneros: summary, critical review e abstract.

${ }^{1}$ Doutora. IFSC (Instituto Federal de Santa Catarina, Florianópolis, Santa Catarina, Brasil). Orcid: https://orcid.org/00000002-6209-3666 E-mail: aline.dib@ifsc.edu.br 
A partir de um questionário de análise de necessidades (em anexo) aplicado no início do ano letivo a uma turma do Ensino Médio/Técnico Integrado em Eletrôncia, de uma instituição federal, os alunos demonstraram 0 interesse em aprender a redigir abstracts. Tal fato ocorreu uma vez que um professor de uma das disciplinas da área técnica solicitou que esses estudantesentregassem um trabalho final escrito, o qual precisaria conter um abstract.

Diante do desafio de trabalhar a produção escrita com estudantes que apresentavam diferentes níveis de conhecimentos da língua inglesa, vi a $A B P$ e a tradução como aliadas. De um lado, a $A B P$ propiciaria aos alunos o engajamento em atividades desafiadoras, o trabalho em grupo e individual, autonomia na aprendizagem, além da produção de um produto final concreto e significativo (NOGUEIRA, 2009). De outro, o GT ajudaria os alunos na escrita de seus textos. As ferramentas de tradução automática são cada vez mais usadas e notavelmente têm passado por aprimoramentos nos últimos anos, em especial o GT. Dessa forma, e já contando que os alunos fariam uso da ferramenta, decidi incorporá-la na prática de sala de aula de forma mais reflexiva.

Para contar essa trajetória, na seção 2, remonto brevemente, a história da tradução e alguns possíveis motivos para o seu abandono e, até mesmo, desprezo na sala de aula de língua adicional. Por outro lado, defendo que a reflexão proporcionada pela prática tradutória é capaz de despertar os alunos para a natureza da linguagem e, também, para questões de ordem política e cultural que envolvem as línguas e sociedades. Na seção 3, exponho a evolução das tecnologias de tradução automática, com destaque para o GT. Na seção 4, trato da ABP e dos motivos para a sua escolha. $\mathrm{Na}$ seção 5 , relato uma prática de sala de aula baseada na ABP e norteada pelo referencial teórico apresentado. Na última seção, apresento as consideraçõs finais.

\section{A tradução e a sala de aula de inglês como língua adicional}

O uso da tradução na sala de aula de inglês como língua adicional não é visto como uma opção para muitos professores. No caso dos cursos livres, as metodologias empregadas, muitas vezes, condenam e inibem seu uso. Uma das hipóteses para que tal fato ocorra está atrelada à forma pela qual a tradução começou a ser introduzida no ensino de línguas. Ainda no Renascimento e com foco no ensino do grego e do latim, surgiu o Método Gramática-Tradução (ROMANELLI, 2006). Contudo, foi a partir de meados do século XIX que tal método difundiu-se no ensino de língua adicional e tinha como características a memorização de vocabulário, o conhecimento de regras gramaticais para empregar as palavras em frases e a execução de exercícios de tradução. Por ter se apresentado como 
um método ineficiente, as metodologias e abordagens que o sucederam (e.g. métodos direto, audiolingual, natural e a abordagem comunicativa) baniram a tradução. Ainda hoje, tal método é erroneamente visto como sendo o único modo de se utilizar a tradução em sala de aula.

Ademais, pelo menos outras duas crenças cooperam para que a tradução caia em descrédito. Uma delas é a premissa colonialista de que um bom professor de língua adicional deva ser falante nativo. Como esse profissional não tem conhecimento da língua materna de seus alunos, a tradução não pode ser um recurso. Paralelo a isso, muitos materiais didáticos são produzidos por editoras internacionais, as quais distribuem os livros para falantes das mais diferentes línguas. Essa homogeneização também apaga as línguas maternas dos materiais e, consequentemente, das salas de aula.

Em relação às escolas, sejam elas públicas ou privadas, por conta do número elevado de alunos por turma e dos diferentes níveis de proficiência linguística dos discentes, percebe-se um uso mais frequente da tradução especialmente na tentativa de minimizar as disparidades. Nesse cenário, muitas vezes, a metodologia empregada na sala de aula de língua adicional é semelhante a do Método Gramática-Tradução. O uso da prática tradutória proposto neste trabalho, contudo, afasta-se completamente dessa visão e alinha-se à ideia de que a tradução deva ser uma temática a ser ensinada e trabalhada em sala de aula assim como tantas outras.

De acordo com Atkinson (1987) e Harbord (1992), a tradução é a estratégia preferida dos alunos e deve ser encarada como um fenômeno natural, uma vez que, independente do professor permiti-la ou não, os estudantes irão comparar itens gramaticais e lexicais da língua alvo com algo semelhante que eles conheçam na língua materna. Assim, ao invés de repreender o aluno quando ele faz uma tradução, seria mais profícuo estimulá-lo através de atividades adequadas, já que os paralelos entre as línguas materna e adicional irão permear o processo de aprendizagem.

Atkinson (1993) elenca, ainda, outros benefícios do uso da tradução em sala de aula como, por exemplo, pensar as línguas comparativamente, desenvolvendo maior consciência sobre as diferenças; refletir sobre o significado das palavras dentro de um contexto, evitando a mecanização que ocorre em exercícios estruturais; considerar a tradução como uma atividade da vida real, mostrando para os alunos que em diferentes ocasiões da vida acadêmica, pessoal e profissional, ele deverá lançar mão desse recurso; estimular os alunos a superar as dificuldades, encorajando-os a dizer aquilo que querem na língua adicional manejando os recursos linguísticos, gramaticais e semânticos que já possuem. 
Nessa mesma linha, Romanelli (2009) defende a reabertura do debate acerca do uso da tradução na sala de aula de línguas e, a partir de autores como Costa (1988), Auerbach (1993), Benucci (1994), e o próprio Atkinson (1987, 1993), apresenta possíveis atividades didáticas que contemplem o uso da tradução como, por exemplo, utilizar a tradução para refletir e colocar em evidência as diferenças e os paralelismos entre as línguas e para promover a discussão de assuntos interculturais.

Na próxima seção, passo a tratar da tradução automática e, mais especificamente, do GT uma vez que é uma ferramenta atual, amplamente usada fora do contexto escolar e que decidi, portanto, trazer para a minha sala de aula a fim de possibilitar que alunos com conhecimentos básicos de língua inglesa, bem como alunos mais proficientes, fossem capazes de fazer melhor uso da ferramenta e aprimorassem seus textos.

\section{A evolução da tradução automática e o Google Tradutor}

Os tradutores automáticos começaram a ganhar destaque juntamente com o avanço da ciência da computação durante a Segunda Guerra Mundial, quando os governos americanos e ingleses engajavam-se na empreitada de entender as mensagens de Japão e Alemanha e, posteriormente, no período da Guerra Fria, com o propósito de obter informações rápidas da inteligência soviética. Contudo, o entusiasmo inicial de se ter uma máquina que pudesse aplicar algoritmos capazes de transmutar um idioma em outro foi arrefecendo, uma vez que os resultados obtidos estavam abaixo do esperado (MATEUS, 1995).

Ao longo da década de 50 , pesquisas na área da tradução automática, com base nas técnicas de linguística computacional e inteligência artificial (MATEUS, 1995), foram conduzidas em importantes instituições como, por exemplo, o Instituto de Tecnologia de Massachussets (MIT) e a Universidade de Georgetown. Já na década de 60, o Conselho Nacional de Pesquisa Americano criou o ALPAC (Automatic Language Processing Advisory Comittee) para avaliar a eficácia dos sistemas de tradução automática existentes. $O$ relatório final apontava as inúmeras dificuldades do processo tradutório através da máquina, o que desacreditou os trabalhos científicos realizados até então. A partir daí, os Estados Unidos, principais financiadores das pesquisas na área, diminuíram drasticamente as verbas, interrompendo os trabalhos e o desenvolvimento da tradução automática (HUTCHINS, 2006).

0 interesse pela tradução por máquinas ressurgiu na década de $80 \mathrm{com}$ a criação da Comunidade Europeia, período em que houve grande informatização e a necessidade de tradução de 
muitos textos para várias línguas. Pouco depois, na década de 90 , a expansão e popularização da internet mudaram a forma de comunicação entre as pessoas e o mundo estava, então, conectado. 0 novo cenário globalizado passou a demandar mais traduções, alavancando, assim, as pesquisas na área da tradução automática (HUTCHINS, 2006) e propiciando o surgimento dos primeiros tradutores online gratuitos.

Uma das ferramentas mais difundidas, o GT, foi disponibilizado em 2006. Em seu surgimento, apenas as línguas inglesa, francesa, alemã e espanhola eram contempladas. Atualmente, as traduções e versões já são realizadas em mais de 100 idiomas (TUROVSKY, 2016). Além disso, outras funcionalidades foram adicionadas como a possibilidade de se ter uma conversa bilíngue, a tradução de imagens de textos em um idioma diferente, o uso da câmera do celular para ver traduções instantâneas, o desenho de letras e caracteres com o dedo e a tradução de textos no modo off-line?2.

Outra evolução significativa foi a das estratégias de tradução utilizadas. Ainda em 2006, era adotada a tradução automática com base em regras (Rule-Based Machine Translation), a qual consistia na transformação de frases de uma língua-fonte em frases de uma língua-alvo a partir de análises morfológicas, sintáticas e semânticas de ambas as línguas. No ano seguinte, em 2007, o GT passou a usar a tradução automática baseada em estatística (Statistical-Based Machine Translation), a qual gerava textos na língua-alvo utilizando estatísticas baseadas em corpus de textos bilíngues. O GT, a partir de métodos quantitativos, buscava padrões em seu corpus para determinar qual a melhor tradução para cada entrada. Dessa forma, as traduções oferecidas oscilavam quanto ao grau de confiabilidade a depender de cada par de línguas, ou seja, os pares com maior volume de traduções já realizadas apresentavam resultados mais confiáveis que as línguas com um número menor de material traduzido. Finalmente, em 2016, o GT começou a fazer uso da tradução automática neural, a qual surgiu a partir do avanço nas pesquisas sobre inteligência artificial. A reprodução da estrutura do cérebro humano sob a forma de redes artificiais em um computador foi possível graças a uma boa capacidade de processamento de dados e à grande disponibilidade de dados, conhecidos como big data, para possibilitar o treinamento das redes neurais (KRÜGER, 2018). Ao invés do uso de algoritmos, o cérebro tradutor artificial aprende a traduzir novos textos autonomamente, deduzindo suas próprias regras, a partir da análise de grande quantidade de dados e da identificação de regularidades e padrões.

Diante dos avanços e da qualidade das traduções oferecidas pelo GT, que aluno de língua adicional não faria uso dessa ferramenta? Por que não, então, trazê-la para a sala de aula? O uso da

2Informações disponíveis em https://translate.google.com/int/pt-BR/about/forbusiness/ 
tradução automática em aula, além de colaborar com o letramento digital dos estudantes, permite que alunos que se acham incapazes de produzir textos em uma língua adicional não se sintam acuados ou silenciados, mas aptos a construir sentidos também em outra língua. Além disso, ao estabelecer paralelos entre as línguas materna e adicional, os ganhos linguísticos ocorrem duplamente.

$\mathrm{Na}$ próxima seção, passo a tratar da $\mathrm{ABP}$, na qual encontrei terreno fértil para desenvolver 0 protagonismo dos estudantes e a cooperação entre eles.

\section{A aprendizagem baseada em projetos}

A ABP (do inglês, Project-based Learning), apesar de estar em evidência na atualidade, remonta aos estudos de John Dewey, ainda no final do século XIX.

Tal abordagem sempre teve em seu cerne aproximar a escola da realidade de vida do aluno, além de colocá-lo como participante ativo no seu processo de aprendizagem. De acordo com Stoller (2006), a ABP é extremamente versátil, o que dificulta elaborar uma definição que abarque as diversas formas que 0 conceito pode ser realizado na prática. Assim, alguns autores (FRIED-BOOTH, 2002; LEFFA; IRALA, 2014; STOLLER, 2006) conceituam a abordagem a partir de um grupo de características. De acordo com Fried-Booth (2002, p.2), por exemplo, o projeto deve ter os alunos como centro e resultar num produto final, o qual fora previamente definido por eles. A autora ressalta, contudo, que é na rota de desenvolvimento do projeto que os alunos adquirem confiança, independência, senso de equipe e cooperatividade.

Nessa mesma direção, Leffa e Irala (2014) apontam que a diferença entre outras atividades de ensino e a ABP está justamente na obtenção de um produto final através de um percurso, chamado pelos autores de "sistema de ação", o qual reúne uma série de tarefas que devem ser realizadas para que se chegue a "algo concreto e significativo para o aluno" (LEFFA; IRALA, 2014, p.38).

Já Stoller (2006, p.24) detalha um pouco mais o "sistema de ação", ou a rota, a ser seguido para que se chegue ao produto final. De acordo com a autora, para que a aprendizagem seja baseada em projetos ela precisa, por exemplo, ser orientada pelo professor quanto ao processo e ao produto final, ter a duração de algumas aulas, incentivar o protagonismo dos estudantes para que eles se sintam parte do projeto e corresponsáveis pelo processo de aprendizagem, estimular o trabalho em grupo, mas também o individual, propiciar que professores e alunos assumam papéis diferentes, ter como produto final algo possível de ser realizado e permitir que os alunos tenham espaço para refletir tanto sobre o processo como sobre o produto. 
Em relação aos novos papéis que devem ser desempenhados por alunos e professores, enquanto os estudantes assumem posição central e postura ativa no processo de ensinoaprendizagem, o professor será aquele que dará suporte e direção ao longo da jornada, deverá deixar claro aonde quer chegar, supervisionará o processo, oferecerá as ferramentas mínimas necessárias, irá questionar e incentivar que o estudante aprofunde o conhecimento (LEFFA; IRALA, 2014; NOGUEIRA, 2009).

Na próxima seção, mostrarei como o repertório teórico apresentado até aqui foi mobilizado na prática da sala de aula.

\section{$5 \mathrm{~A}$ aprendizagem baseada em projetos na sala de aula de inglês como língua adicional}

Este trabalho foi desenvolvido com uma turma de último ano do Ensino Médio/Técnico Integrado em Eletrônica. A carga horária da disciplina é de dois tempos de cinquenta e cinco minutos cada, sempre ofertados de forma conjunta.

O grupo em questão era composto de dezoito estudantes e eu seria a professora da turma pela primeira vez. Dessa forma, no primeiro dia de aula (Aula ${ }^{3}$ ), apliquei um questionário elaborado no Google Forms, cujo objetivo era conhecer melhor os alunos e entender quais as suas necessidades. Acredito na importância do uso de questionários para esse fim, pois quando os alunos param por alguns minutos para refletir sobre suas necessidades e o professor toma conhecimento delas, "0 processo de conscientização pode interferir não apenas no conteúdo, mas também na metodologia adotada para a aprendizagem" (HUTCHINSON; WATERS, 1987, p.53). Para que os estudantes respondessem ao questionário, levei-os a uma sala equipada com vinte e seis computadores ligados à internet e dispostos em carteiras individuais, enfileiradas e de frente para o quadro branco. Na mesa do professor, havia mais um computador com acesso à internet, além da presença de um projetor fixo no teto e de sistema de home theater.

Em relação às perguntas 14 (What do you think you need to study more? For example, I need more speaking practice, more grammar, etc...) e 15 (Why do you think so?) do questionário, do total de alunos, quatorze afirmaram que gostariam de desenvolver a escrita, principalmente a de abstracts, pois, estavam envolvidos em um trabalho para uma das disciplinas da área técnica, o qual demandaria a produção desse gênero textual, como explicitado na Introdução. Diante do desejo apresentado pelos alunos, optei, então, por desenvolver um projeto com a turma, o qual teria a duração de um bimestre

\footnotetext{
${ }^{3}$ Esse encontro foi nomeado de "Aula 0", pois foi uma aula de apresentações e de aplicação do questionário de análise de necessidades. A "Aula 1" marca o início do projeto.
} 
letivo, totalizando dez aulas ${ }^{4}$. Além de trabalhar com 0 abstract, o qual seria 0 nosso produto final, decidi incluir na proposta a produção de resumos textuais e resenhas críticas de livros e séries. Tal inclusão se deu pelo fato de os alunos terem apontado livros e séries como assuntos de interesse na questão 16 do questionário (Give your teacher some suggestions of topics you are interested in). Dessa forma, resolvi iniciar a proposta partindo de algo lúdico que fosse progredindo para um tópico de relevância acadêmica com o intuito de atraí-los e engajá-los.

Assim, para o desenvolvimento do projeto, segui as etapas abaixo, as quais passo a descrever.

\subsection{Aula 1: apresentação da proposta}

Após analisar os questionários, decidi, então, que iria trabalhar a produção escrita e também com a ABP. A escolha pelo projeto se deu, principalmente, pelo fato de ter alunos ainda dando os primeiros passos na aprendizagem do inglês, enquanto outros já demonstravam bastante fluência no idioma. A ABP permitiria um trabalho mais cooperativo entre os alunos, além de propiciar que os discentes escolhessem a melhor rota para chegar ao produto final, havendo um maior respeito acerca do tempo de cada estudante.

Assim, nessa aula, apresentei a eles a estrutura do projeto a cada encontro. Optei por dar instruções iniciais acerca dos próximos passos para que eles se sentissem seguros e entendessem a proposta. Como seria muito importante o acesso aos computadores e à internet, passei a realizar todas as nossas aulas na mesma sala onde apliquei o questionário.

\subsection{Aula 2: o uso do Google Tradutor}

Esse encontro trouxe surpresas para os alunos, pois eles afirmaram achar diferente poder usar o GT nas aulas de inglês. Alguns relataram que sempre foram desencorajados e, até mesmo, proibidos de utilizá-lo. Expus a eles, então, que, a partir do uso da ferramenta, passaríamos a refletir sobre as diferenças de estrutura entre as línguas inglesa e portuguesa. Para ajudá-los a melhorar os resultados

\footnotetext{
4 Uma aula foi disponibilizada para a aplicação do questionário de análise de necessidades (Aula 0) e nove aulas, para 0 desenvolvimento do projeto (Aulas 1 a 9 ).
} 
das traduções oferecidas pelo Google, preparei slides com algumas orientações e, durante a explicação, propus que eles abrissem o GT e fossem testando as possibilidades junto comigo.

A primeira orientação teve relação, justamente, com as diferenças de estrutura de ambos os idiomas. Diante da ordem mais rígida do inglês na organização dos elementos dentro da oração, sugeri aos alunos que, antes de lançarem o texto no tradutor, eles o escrevessem em português, contudo, seguindo a ordem menos flexível do inglês de, primeiramente, colocar o sujeito, o qual está sempre presente, o verbo, os complementos dos verbos (objetos diretos e indiretos), quando fosse o caso, e os demais complementos (advérbios). Inicialmente, dei algumas orações em português para que eles digitassem no tradutor (Oração 1). Depois, ofereci as mesmas orações escritas em português, contudo, seguindo a ordem do inglês (Oração 2) e pedi que eles comparassem os resultados das traduções feitas pelo GT, como pode ser observado no exemplo 1 abaixo.

\section{Exemplo 1:}

Oração 1: Ontem, fui pela manhã com minha mãe ao mercado e comprei frutas.

Tradução feita pelo GT: Yesterday, I went to the market with my mother in the morning and bought fruits.

Oração 2: Ontem pela manhã, eu fui ao mercado com minha mãe e comprei frutas.

Tradução feita pelo GT: Yesterday morning, I went to the market with my mother and bought fruits.

Todos foram capazes de perceber que, na segunda vez, as traduções feitas pela ferramenta praticamente não precisavam de correções. Após esse momento em conjunto, dei mais alguns minutos para que eles criassem suas próprias orações e fizessem os testes. Durante essa atividade, os alunos foram verbalizando suas percepções e as diferenças estruturais que encontravam, conforme iam fazendo as traduções.

A segunda orientação teve a ver com as palavras-chave dos textos e como checar se a tradução feita pela ferramenta foi adequada. Nesse momento, não mencionei os abstracts, mas já sabia que essa discussão seria importante para quando eles fossem produzi-los. Para tratar do assunto, mostrei aos discentes como fazer uma nuvem de palavras (word cloud) usando o site Tagxedo ${ }^{5}$. Nessas nuvens, cada palavra tem seu tamanho redigido de acordo com sua relevância

\footnotetext{
${ }^{5}$ A nuvem de palavras pode ser construída em http://www.tagxedo.com/.
} 
dentro do texto. Quanto mais vezes a palavra se repetir num determinado texto, maior ela será dentro da nuvem. Sugeri, então, que os alunos utilizassem a letra de sua música favorita em inglês para construir suas nuvens e observar quais eram os vocábulos mais importantes. Após essas atividades, trazendo a discussão novamente para o campo da tradução, mostrei a relevância dos alunos voltarem seus olhares para as palavras-chave do texto, pois, qualquer inadequação na tradução poderia causar prejuízos mais sérios para a compreensão. Dessa forma, mostrei a eles como usar o Google Imagens para checar, principalmente, substantivos concretos e também o site Linguee ${ }^{6}$, para termos mais específicos.

O último tópico que abordei nesse encontro foi acerca da importância de se manter os sujeitos das orações no texto de partida para que o tradutor automático não perdesse a referência. Se 0 período for longo e houver recorrência de sujeitos ocultos, a chance do tradutor automático se equivocar na hora de fazer uma referência pronominal aumenta. Nesse momento, aproveitei para revisar os pronomes em inglês e sugeri alguns períodos para que os estudantes digitassem no tradutor e comparassem-nos quanto à presença ou não do sujeito e ao resultado das referências pronominais oferecidas pela ferramenta, como pode ser visto no exemplo 2 abaixo.

\section{Exemplo 2:}

Oração 1 (com sujeitos ocultos): A mãe de Pedro entrou com o carro na garagem e foi direto ao banheiro. Depois, preparou o almoço e levou o filho mais novo à escola.

Tradução feita pelo GT: Pedro's mother drove into the garage and went straight to the bathroom. Then he prepared lunch and took his younger son to school.

Oração 2 (com a presença dos sujeitos): $\underline{\text { A mãe de Pedro entrou com o carro na garagem e ela }}$ foi direto ao banheiro. Depois, ela preparou o almoço e ela levou 0 irmão mais novo à escola. Tradução feita pelo GT: Pedro's mother drove the car into the garage and she went straight to the bathroom. Afterwards, she prepared lunch and she took the younger son to school.

Através das orações acima, os alunos puderam perceber que, quando os sujeitos estavam ocultos, a ferramenta de tradução perdeu o referencial e interpretou que quem preparou o almoço e levou o filho mais novo à escola foi Pedro. Em relação à segunda oração, como os sujeitos foram 
mantidos, o GT fez as referências corretamente. Nesse momento, foi possível mostrar aos alunos que, no caso das orações coordenadas, o sujeito em inglês também poderia ficar oculto e o trecho ficaria mais bem escrito se os dois pronomes she que aparecem após 0 and fossem removidos.

Por fim, apresentei o nome de alguns dicionários e mostrei, de forma breve, como usá-los, focando, principalmente, na importância de se saber a classe gramatical da palavra que se está buscando, além da procura por palavras primitivas.

\subsection{Aula 3: summary}

O foco dessa aula foi discutir o gênero resumo textual (summary). Sugeri que, individualmente, os alunos buscassem na rede, pelo menos, dois resumos de suas séries, filmes ou livros favoritos. $\mathrm{Na}$ sequência, mostrei a eles, através do projetor, um resumo ${ }^{7}$ do livro The Handmaid's Tale, de Margaret Atwood (1986). Os alunos, no geral, já haviam ouvido falar da obra, mas ninguém havia lido o livro ou assistido à série. Como o resumo que apresentei era mais extenso e detalhado, sugeri que o lêssemos em conjunto e os alunos foram se voluntariando e lendo em voz alta. Ao longo da leitura, discutimos alguns vocábulos novos e os alunos se engajaram em um debate acerca da temática.

A partir do resumo mais detalhado e de alguns cartazes ${ }^{8}$ da série que apresentei, abri um arquivo de texto do Google e sugeri a escrita coletiva de um novo resumo em inglês para a obra em discussão. Com o uso do projetor, fui acompanhando a produção dos alunos e colaborando, quando solicitada. Cada aluno foi escrevendo os detalhes que lembrava e, ao final, colaborativamente, foram unindo as informações e tornando o texto coeso. Esse foi um ótimo momento para trazer à tona a importância dos marcadores discursivos, mostrar as diferenças de uso entre eles e cooperar com os alunos quanto às escolhas feitas.

\subsection{Aula 4: critical review}

O objetivo desse encontro era tratar do gênero resenha crítica (critical review). Logo de início, apresentei aos estudantes o conto There was Once, também de Margaret Atwood (1992). Nesse texto, a autora problematiza os estereótipos da cultura ocidental contidos nos contos de fada a partir da conversa entre um escritor e seu interlocutor. Este faz diversas indagações a cada tentativa daquele de

\footnotetext{
70 resumo pode ser encontrado em https://www.sparknotes.com/lit/handmaid/summaryl

8 Alguns dos cartazes podem ser vistos em https://www.fanpop.com/clubs/hulu/images/41598473/title/handmaids-taleposter-photo
} 
iniciar um conto. Todos os aspectos que compõem o gênero, como, por exemplo, o fato de a mocinha ser bonita, pobre, branca, morar com sua madrasta e de a história terminar em matrimônio, são questionados.

A partir dessa desconstrução presente no texto, os próprios alunos sugeriram pensarmos em como seria uma protagonista que não seguisse os padrões. Novamente, fazendo uso de um documento do Google, os alunos, de forma coletiva e colaborativa, começaram a escrever sobre como seria a protagonista da história. Três estudantes iniciaram a descrição de suas personagens e os demais foram se engajando nesses textos. Vale ressaltar que a produção escrita se deu em inglês, contou com a participação de todos e foi algo totalmente proposto e conduzido pelos próprios estudantes. Foi um momento lúdico, mas também de boas reflexões acerca de narrativas e performances de feminilidade e masculinidade naturalizadas (BUTLER, 1990). Em seguida, fiz a apresentação das características de uma resenha crítica e solicitei que os alunos, em duplas, escrevessem uma acerca do conto de Atwood.

\subsection{Aula 5: o que é um abstract e como escrevê-lo}

O objetivo aqui era tratar do gênero abstract. A maioria dos alunos relatou que tomou conhecimento desse gênero textual por conta da solicitação do professor da área técnica. Através de slides, mostrei para os alunos as características do gênero e, partindo de exemplos retirados de periódicos, analisamos diversos abstracts, inclusive, de áreas diferentes. Retomei, ainda, a questão das palavras-chave, que havíamos discutido na Aula 2, e pedi que os alunos as observassem. Aproveitei o momento para falar sobre buscas no Google Acadêmico e sobre os periódicos online aos quais eles poderiam ter acesso através da biblioteca da instituição.

\subsection{Aula 6: a escrita do abstract em língua portuguesa}

Como o trabalho da área técnica seria entregue em duas semanas, os alunos já tinham seus temas bem definidos e dois dos quatro grupos estavam com o texto quase finalizado. Nesse encontro, portanto, solicitei que os estudantes redigissem seus abstracts em língua portuguesa. Assim, dois grupos conseguiram finalizar o texto durante a aula e os outros dois deixaram a parte dos resultados para ser concluída posteriormente. 


\subsection{Aula 7: a escrita dos abstracts}

Nessa aula, os alunos deveriam verter 0 abstract em língua portuguesa que haviam feito no encontro anterior para o inglês. Todos os grupos fizeram uso do GT nesse momento. Contudo, foi interessante percebê-los mobilizando o que aprenderam nos encontros anteriores para essa tessitura.

Vale ressaltar que, enquanto circulava pelos grupos e os questionava acerca de determinadas escolhas, isso permitia que os alunos refletissem e justificassem os critérios adotados (ROMANELLI, 2006). Como exemplo, posso citar o uso do pronome relativo onde. Em três dos quatro grupos, indaguei os estudantes acerca da presença do where nos abstracts e o porquê de ele estar sendo usado. Em todos os três grupos, os alunos perceberam que a referência não se tratava de um lugar e que, portanto, o pronome relativo where não era a melhor opção. Contudo, a culpa para a inadequação recaiu sobre o Google. Sugeri, então, que eles revisitassem o abstract em português e, para a surpresa deles, o pronome "onde" estava no texto de partida. Nesse momento, os alunos puderam pesquisar qual seria o melhor pronome relativo para ser usado tanto em português quanto em inglês.

\subsection{Aula 8: avaliação coletiva dos abstracts}

O objetivo do encontro era que os alunos tivessem acesso aos abstracts uns dos outros e os analisassem. Dessa forma, projetei os textos sem identificação de autoria e, um a um, fomos examinando tanto a parte da estrutura dos abstracts quanto questões relacionadas à gramática, vocabulário, coesão e coerência. Fizemos, ainda, a comparação dos abstracts em inglês e português e, mais uma vez, observamos as diferenças entre as línguas. Pedi que, ao final de cada análise, os alunos emitissem uma opinião utilizando os conceitos "bom", "regular" ou "precisa de melhorias". Três dos quatro abstracts ganharam o conceito máximo e apenas um ganhou o conceito "regular", uma vez que, segundo os alunos, não havia apresentado os resultados de forma clara. 0 grupo que ganhou 0 conceito mais baixo se justificou afirmando que não havia concluído o trabalho da área técnica e que, por esse motivo, os resultados não tinham sido totalmente apresentados.

\subsection{Aula 9: a avaliação do projeto}


No último encontro, dei meu retorno final para os abstracts produzidos. Diante de tudo o que já havíamos discutido e construído aula a aula, minhas correções foram mínimas. Nessa aula, o objetivo era que eles avaliassem tudo o que fizemos até ali e, para tal, propus um bate-papo. Durante a nossa conversa, fiz anotações acerca dos pontos arrolados pelos alunos.

Inicialmente, indaguei o que eles gostariam que tivesse sido diferente e o único ponto elencado foi a falta de tempo para escrever um conto de fadas a partir das protagonistas que criaram na Aula $4 \mathrm{e}$ para prosseguir com as discussões da Aula 3. Como aspectos positivos, os alunos mencionaram que a forma como a escrita foi se desenvolvendo os preparou para o momento da redação do abstract. Praticamente todos os estudantes pontuaram a tranquilidade com a qual eles conseguiram realizar 0 produto final e que tal fato era inimaginável quando o projeto Ihes foi apresentado. Ademais, eles assinalaram que a data acordada para escrevermos o abstract em aula ajudou-os na organização de um cronograma para concluir o trabalho da área técnica a tempo. Outro ponto levantado foi que as reflexões feitas sobre ambas as línguas os ajudaram na produção do texto também em português para a área técnica. Além disso, a forma como vimos os pronomes e os marcadores discursivos sendo empregados na prática, por exemplo, tornou a aprendizagem mais significativa. Por fim, todos afirmaram que gostariam de participar de novos projetos.

\section{Considerações Finais}

O objetivo deste trabalho foi apresentar uma prática de sala de aula de inglês como língua adicional, cujo propósito foi a produção de três gêneros textuais (summary, critical review e abstract) com o auxílio do GT. Para tal, lancei mão de componentes da aprendizagem baseada em projetos, os quais auxiliaram a trajetória dos alunos no processo de escrita.

Acredito que optar por esse caminho trouxe ganhos como, por exemplo, um melhor entendimento por parte dos alunos acerca de estruturas da língua inglesa a partir de um contraste com a língua materna, mais confiança dos alunos durante o momento da escrita, ampliação de vocabulário em língua inglesa, maior atenção aos elementos coesivos dos textos em ambas as línguas, conhecimento acerca de um gênero textual, no caso, o abstract, o qual será muito proveitoso para a vida universitária, melhora considerável no uso de dicionários e na identificação de classes gramaticais para uma busca mais acurada, e uso reflexivo da ferramenta de tradução automática permitindo que os alunos tivessem segurança na hora de promover ajustes no texto oferecido pela máquina. 
Vale ressaltar que 0 processo de escuta dos estudantes permite que o professor torne 0 ensino-aprendizagem mais significativo e prazeroso. Assim, no bimestre seguinte, dei continuidade ao trabalho de produção textual e nos engajamos na escrita de contos e histórias em quadrinhos.

\section{Referências}

ATKINSON, D. The mother tongue in the classroom: a neglected resource? ELT Journal, v. 41, n.4, p. 241-247, 1987. https://doi.org/10.1093/elt/41.4.241

ATKINSON, D. Teaching Monolingual Classes. Essex: Longman Group UK Limited, 1993.

ATWOOD, M. E. The Handmaid's Tale. New York: Anchor Books, 1986.

ATWOOD, M. There was Once. In: Good Bones. Toronto: Coach House Press, 1992. p. 133-134.

AUERBACH, Ernest. Reexamining English only in the ESL classroom. Tesol Quarterly, v. 27, n. 1, spring 1993, p. 9-30.

BENUCCI, A. La grammaticanell'insegnamentodell'italiano a stranieri. Roma: Bonacci Editore, 1994.

BUTLER, J. Gender Trouble. Feminism and the Subversion of Identity. New York: Routledge, 1990.

COSTA, W. C. Tradução e ensino de línguas. In: BOHN H. I.; VANDRESEN, P. Tópicos de Lingüística Aplicada ao ensino de línguas estrangeiras. Florianópolis: Editora da UFSC, 1988, p. 282-291.

FRIED-BOOTH, D. Project Work. New York: Oxford University Press, 2002.

HARBORD, J. The use of the mother tongue in the classroom. ELT Journal, v. 46, n. 4, October, 1992, p. $350-355$.

HUTCHINS, J. Machine Translation: History. In: BROWN, K (Ed.). Encyclopedia of Language \& Linguistics. 2nd ed., v. 7. Oxford: Elsevier, 2006, p. 375-383. Disponível em: http://www.hutchinsweb.me.uk/EncLangLing-2006.pdf. Acesso em 23 set. 2020. https://doi.org/10.1016/B0-08-044854-2/00937-8

HUTCHINSON, T.; WATERS, A. English for Specific Purposes - A learning-centered approach. Cambridge: Cambridge University Press, 1987.

KRÜGER, R. Multilinguismo à Luz da Tradução Automática. Revista Humboldt Online, São Paulo, abr. 2018. Seção Cultura. Disponível em: https://www.goethe.de/ins/br/pt/kul/mag/21250571.html. Acesso em 09 jun. 2020.

LEFFA, V.; IRALA, V. O ensino de outra(s) língua(s) na contemporaneidade: questões conceituais e metodológicas. In: __ _ _. (Org.). Uma espiadinha na sala de aula: ensinando línguas adicionais no Brasil. Pelotas: Educat, 2014. p. 21-48. 
MATEUS, M. H. Tradução automática: um pouco de história. In: ; BRANCO, A. (Org.) Engenharia da Linguagem. Lisboa: Edições Colibri, 1995, p. 115-120.

NOGUEIRA, N. Pedagogia dos projetos: etapas, papéis e atores. 4. ed. São Paulo: Érica, 2009.

ROMANELLI, S. O uso da tradução no ensino-aprendizagem das línguas estrangeiras. Revista Horizontes de Linguística Aplicada, v. 8, n. 2, p. 200-219, 2009. Disponível em: file:///C:/Users/Valmir/Downloads/pattyatma-editor-da-revista-2942-8852-1-sm.pdf Acesso em 23 abr 2021.

ROMANELLI, S. Traduzir ou não traduzir em sala de aula? Eis a questão. Revista Inventário. 5. ed., 2006. Disponível em: http://www.inventario.ufba.br/05/05sromanelli.htm. Acesso em 05 jun. 2020.

STOLLER, F. Establishing a theoretical foundation for project-based learning in second and foreign language contexts. In: BECKETT, G.; MILLER, P. Project-based second and foreign language education: past, present, and future. Greenwich: Information Age Publishing, 2006. p. 19-40.

TUROVSKY, B. Ten Years of Google Translate. The Keyword. 28 abr. 2016. Disponível em:https://www.blog.google/products/translate/ten-years-of-google-translate/Acesso em 22 abr. de 2021. 


\section{Anexo}

Needs Analysis Questionnaire (adapted from Google Forms)

1) Age:

2) Course:

3) In your opinion, which is your English level?
a) Basic
b) Low Intermediate
c) Upper Intermediate
d) Advanced

4) Put the abilities below into order. 1 stands for the ability you manage the most and 5 , the least.

\begin{tabular}{|c|l|l|l|l|}
\hline speaking & listening & writing & reading & translating \\
\hline
\end{tabular}

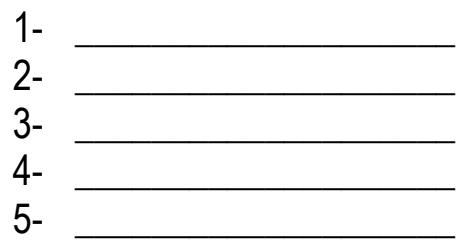

5) What do you do to brush up on your English?

6) When/Where do you use the English language?

7) Do you like the vocational course you've chosen?

8) Why do you want to learn English?

9) Do you know any other language? ___ If so, what language(s) do you know?

10) Where did you learn English? For example, at a private course, playing video games, etc. Talk a little bit about your learning experience(s).

11) Do you like studying English at IFSC?

12) What do you like the most about it?

13) What do you like the least?

14) What do you think you need to study more? For example, I need more speaking practice, more grammar, etc...

15) Why do you think so?

16) Give your teacher some suggestions of topics you are interested in:

Data de submissão: 11/03/2021. Data de aprovação: 28/04/2021. 